\title{
Insertion of the 3' ABL region into the long arm of chromosome 1 in a Philadelphia chromosome-negative chronic myeloid leukemia case
}

\author{
WALID AL-ACHKAR ${ }^{1}$, THOMAS LIEHR ${ }^{2}$ and ABDULSAMAD WAFA ${ }^{1}$ \\ ${ }^{1}$ Molecular Biology and Biotechnology Department, Human Genetics Division, Atomic Energy Commission of Syria, \\ Damascus, Syria; ${ }^{2}$ Jena University Hospital, Institute of Human Genetics and Anthropology, Jena, Germany
}

Received June 9, 2010; Accepted August 18, 2010

DOI: $10.3892 / \mathrm{ol} .2010 .180$

\begin{abstract}
Chronic myeloid leukemia (CML) is a pluripotent hematopoietic stem cell disorder almost always characterized by the presence of the Philadelphia chromosome $(\mathrm{Ph})$, usually due to $\mathrm{t}(9 ; 22)(\mathrm{q} 34 ; \mathrm{q} 11)$. The presence of $\mathrm{Ph}$ results in the formation of the BCR/ABL fusion gene, which is a constitutively activated tyrosine kinase. Approximately $1 \%$ of $\mathrm{CML}$ patients appear to have a $\mathrm{Ph}$-negative karyotype but carry a cryptic BCR/ABL fusion that can be located by fluorescence in situ hybridization (FISH) at chromosome 22q11, 9q34 or a third chromosome. This study investigated a rare $\mathrm{Ph}$-negative CML case with insertion of the $3^{\prime}$ ABL region into the long arm of derivative chromosome 1 but lacking the 5' BCR region on $\operatorname{der}(22)$.
\end{abstract}

\section{Introduction}

Chronic myeloid leukemia (CML) is a pluripotent hematopoietic stem cell disorder defined by expression of the BCR/ABL fusion gene, a constitutively activated tyrosine kinase, harbored by the Philadelphia chromosome $(\mathrm{Ph})$, which is the result of a $\mathrm{t}(9 ; 22)(\mathrm{q} 34 ; \mathrm{q} 11)$ or a related variant translocation (1). In approximately $1 \%$ of CML patients, bone marrow cells appear to be Ph-negative by G-banding, although the BCR/ABL fusion gene can be identified by molecular means and can be located by fluorescence in situ hybridization (FISH) on chromosome $22 q 11,9 q 34$ or even a third chromosome (2-5). Cases of Ph-negative BCR/ABL-positive CML with the chimeric gene present on derivative chromosome $\operatorname{der}(22)$, as in the majority of CML cases, or alternatively on $\operatorname{der}(9)$ appear to have the same

Correspondence to: Dr Walid Al Achkar, Molecular Biology and Biotechnology Department, Human Genetics Division, Atomic Energy Commission of Syria, P.O. Box 6091, Damascus, Syria E-mail: ascientific@aec.org.sy

Key words: Philadelphia chromosome negative, chronic myeloid leukemia, BCR/ABL rearrangement, fluorescence in situ hybridization clinical and molecular characteristics as Ph-positive patients. However, a worse prognosis associated with the location of BCR/ABL on der(9) was previously noted (6-9).

The biology and clinical significance of genetic rearrangements in $\mathrm{Ph}$-negative $\mathrm{BCR} / \mathrm{ABL}$-positive disease was evaluated following initial descriptions (2-5). Two mechanisms involved in the formation of the chimeric gene in masked Ph-positive cells have been postulated: insertion of $\mathrm{ABL}$ into the $\mathrm{BCR}$ region (or vice versa), or by a multiple-step model where a classical $t(9 ; 22)$ is followed by translocation of the two products and/or another autosome, thereby restoring the normal chromosome morphology. In both instances, more than the 2 breaks associated with classical $t(9 ; 22)$ are implicated (10).

This study investigated a rare CML case, Ph-negative, with an insertion of the $3^{\prime} \mathrm{ABL}$ region into the long arm of derivative chromosome 1 and lacking the $5^{\prime} \mathrm{BCR}$ region on $\operatorname{der}(22)$.

\section{Materials and methods}

Case report. In July 2005, a female patient, 31 years of age, presented for the first time with a whole blood cell count (WBC) of $35.07 \times 10^{9} / 1$ (72.3\% neutrophils, $13 \%$ lymphocytes, $1.16 \%$ eosinophiles, $5.7 \%$ monocytes, $4.1 \%$ basophiles and $3.6 \%$ immature cells). The platelet count was $381 \times 10^{9} / 1$, and the hemoglobin level was $9.8 \mathrm{~g} / \mathrm{dl}$. A physical examination showed no splenomegaly, although loss of weight was noted. Results of a chromosome analysis using banding cytogenetics showed a karyotype in concordance with the clinical diagnosis of CML in the chronic phase (CP). The patient was treated with hydroxyurea (1500 mg daily dose) for a duration of two years and eleven months. In June 2008, the patient presented for the second time with a WBC count of $20.86 \times 10^{9} / 1$ (73\% neutrophils, $15.2 \%$ lymphocytes, $1.2 \%$ eosinophiles, $5.3 \%$ monocytes and $5.3 \%$ basophiles). The platelet count was $497 \times 10^{\%} / 1$, and the hemoglobin level was $12.9 \mathrm{~g} / \mathrm{dl}$. Serum lactate dehydrogenase (LDH) was $1274 \mathrm{U} / 1$ (normal up to $460 \mathrm{U} / \mathrm{l}$ ), serum alanine aminotransferase was $54 \mathrm{U} / 1$ (normal up to $40 \mathrm{U} / \mathrm{l}$ ) and serum aspartate aminotransferase was $41 \mathrm{U} / 1$ (normal up to $40 \mathrm{U} / \mathrm{l}$ ). The patient was treated with hydroxyurea $(1500 \mathrm{mg}$ daily dose), but was subsequently lost during follow-up. 


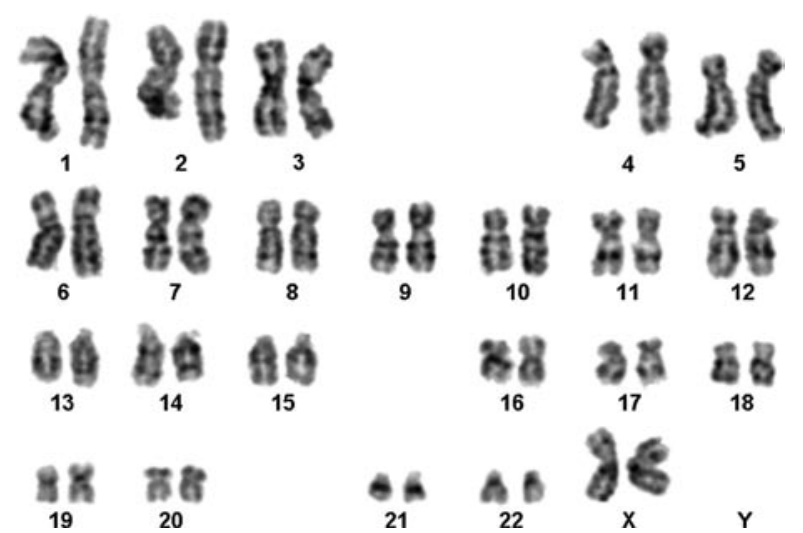

Figure 1. GTG-banding revealed a karyotype 46,XX.

Banding cytogenetics. Banding cytogenetics using the GTG-method was conducted according to standard procedures (11). A total of 20 metaphases derived from the unstimulated

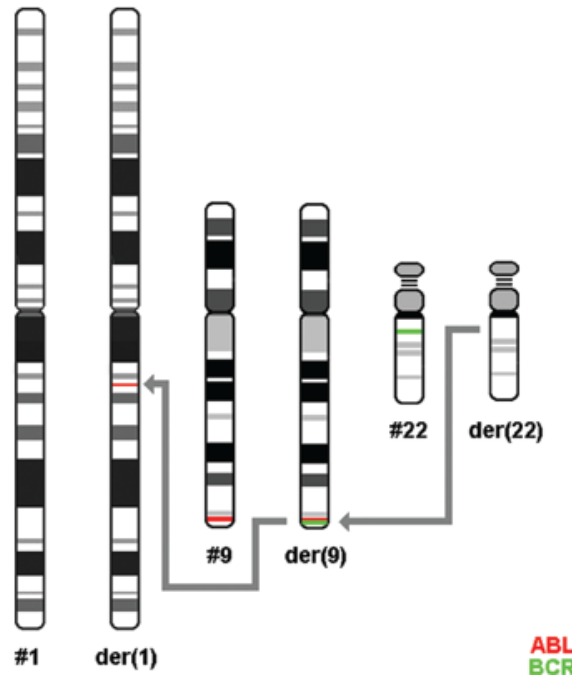

Figure 3. Schematic representation of chromosomal changes that occurred in the patient. The BCR/ABL probe showed a fusion signal on der(9) and insertion of $3^{\prime} \mathrm{ABL}$ on der(1). The 5' region of $\mathrm{BCR}$ was deleted on der(22) while the $3^{\prime}$ region of BCR remained on chromosome 22. \#, chromosome; der, derivative chromosome.

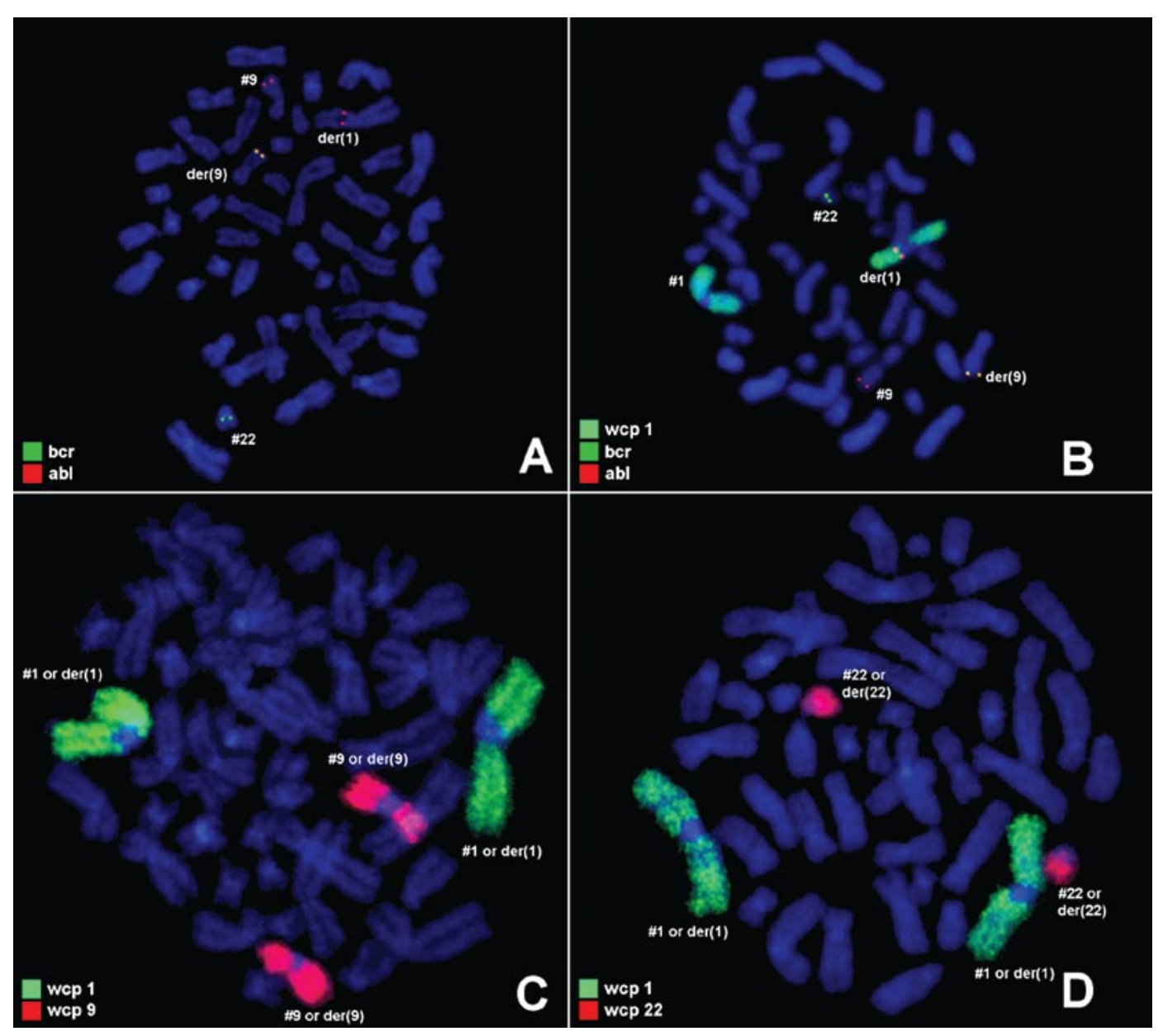

Figure 2. Karyotype and chromosomal aberrations were unconfirmed using molecular cytogenetic approaches. (A) The BCR/ABL fusion gene was absent on $\operatorname{der}(22)$, while the ABL/BCR fusion gene was observed on der(9). Insertion of the $3^{\prime}$ ABL region into the long arm on der(1) and lack of the 5' BCR region on der(22) were noted. (B) The BCR/ABL fusion gene was absent on der(22), while the ABL/BCR fusion gene was observed on der(9). Insertion of the 3' ABL region into the long arm on der(1) confirmed by using wcp1 and lack of the 5' BCR region on der(22) were noted. (C) The application of FISH using wcp for chromosomes 1 and 9 did not reveal a translocation between these chromosomes. (D) The application of FISH using wcp for chromosomes 1 and 22 did not reveal a translocation between these chromosomes. \#, chromosome; der, derivative chromosome; $\mathrm{Ph}$, Philadelphia-chromosome. 
bone marrow of the patient were analyzed individually. Karyotypes were described according to the International System for Human Cytogenetic Nomenclature (12).

Fluorescence in situ hybridization. FISH using BCR/ABL dual-color dual fusion translocation probe (Abbott Molecular/ Vysis, USA) and whole chromosome painting (wcp) probe for chromosomes 1, 9 and 22 (MetaSystems, Germany) were applied as previously described (11). A total of 50 metaphase spreads were analyzed, each using a fluorescence microscope (Axio Imager.Z1 mot; Zeiss) equipped with appropriate filter sets to discriminate between a maximum of five fluorochromes and the counterstain DAPI (4',6-diamino-2-phenylindole). Image capturing and processing were carried out using an image analysis system (MetaSystems, Altlussheim, Germany).

\section{Results}

A normal karyotype 46,XX was determined in the GTG-banding (Fig. 1) and was further studied by molecular cytogenetics (Fig. 2). Dual-color-FISH using probes specific for $\mathrm{BCR}$ and $\mathrm{ABL}$ revealed that the $\mathrm{BCR} / \mathrm{ABL}$-translocation fusion gene was absent on $\operatorname{der}(22)$. However, the presence of the ABL/BCR-translocation fusion gene on $\operatorname{der}(9)$, insertion of the $3^{\prime} \mathrm{ABL}$ region on der(1) and lack of the 5' BCR region on der(22) were noted (Fig. 2A and B). Moreover, FISH using wcp1, wcp9 and wcp22 probes did not show a translocation between chromosome 1 and 9 or chromosome 1 and 22 (Fig. 2C and D). Thus, the result obtained was: 46,XX,ins $(1 ; 9)$ (q21.3;q34q34),ins(9;22)(q34;q11q11),del(22)(q11q11).

\section{Discussion}

The present study identified one additional chromosomal alteration, insertion of the $3^{\prime} \mathrm{ABL}$ region on $\operatorname{der}(1)$, in a Ph-negative BCR/ABL-positive CML-CP case. To the best of our knowledge, the insertion of the ABL region into der(1) has never been described in CML (13).

According to the literature, two alternative mechanisms were postulated to elucidate the formation of a fusion gene in Ph-negative BCR/ABL-positive CML patients $(10,14)$. The first mechanism involves a one-step model where BCR/ABL results from a simple insertion of either 3' ABL1 into BCR or 5' BCR into ABL after three genomic breaks. The second mechanism is a multiple-step model involving an initial classical $\mathrm{t}(9 ; 22)(\mathrm{q} 34 ; \mathrm{q} 11)$ followed by a second translocation of the two products and/or a third chromosome, requiring a minimum of 4 genomic breaks (14).

In the present case, FISH results led to the conclusion that insertion of 5' BCR sequences within the ABL gene transpired while 3' BCR sequences remained on chromosome 22 (Fig. 3). Previous studies on other Ph-negative patients with the BCR-ABL fusion gene at $9 q 34$ also proposed the insertion of chromosome 22 sequences into chromosome 9 as the more likely mechanism, as opposed to one involving two consecutive translocations. This event appears more likely as it requires only two breaks at chromosome 22 and one at chromosome 9 instead of a total of four breaks involved in the double-consecutive translocation (15).
A second event, insertion of 3 ' ABL sequences on der(1), possibly shifted ABL from der(22) to the long arm of chromosome 1 . The 5 ' region of the BCR gene was deleted on der(22). The patient presented with CML-CP. Thus, the second event may be the evolution of a Ph-negative karyotype.

In conclusion, regarding the karyotype observed in the present case with the insertion mechanism, a minimum of five breaks are required; one on chromosome 1, two on chromosome 9 and two on chromosome 22, to explain the insertion and deletion.

\section{Acknowledgements}

We thank Professor I. Othman, Director General of the Atomic Energy Commission of Syria (AECS) and Dr N. Mirali, Head of the Molecular Biology and Biotechnology Department for their support. This work was supported by the Syrian Atomic Energy Commission, in part, by the Stefan-Morsch-Stiftung, Monika-Kutzner-Stiftung and the DAAD (D/07/09624).

\section{References}

1. Melo JV and Barnes DJ: Chronic myeloid leukaemia as a model of disease evolution in human cancer. Nat Rev Cancer 7: 441-453, 2007.

2. Hagemeijer A, de Klein A, Godde-Salz E, Turc-Carel C, Smit EM, van Agthoven AJ and Grosveld GC: Translocation of c-abl to 'masked' $\mathrm{Ph}$ in chronic myeloid leukemia. Cancer Genet Cytogenet 18: 95-104, 1985.

3. Morris CM, Reeve AE, Fitzgerald PH, Hollings PE, Beard ME and Heaton DC: Genomic diversity correlates with clinical variation in $\mathrm{Ph}$ '-negative chronic myeloid leukaemia. Nature 320: 281-283, 1986.

4. Hagemeijer A, Buijs A, Smit E, Janssen B, Creemers GJ, Plas D van der and Grosveld G: Translocation of BCR to chromosome 9: a new cytogenetic variant detected by FISH in two Ph-negative, BCR-positive patients with chronic myeloid leukemia. Genes Chromosomes Cancer 8: 237-245, 1993.

5. Nacheva E, Holloway T, Brown K, Bloxham D and Green AR: Philadelphia-negative chronic myeloid leukaemia: detection by FISH of BCR-ABL fusion gene localized either to chromosome 9 or chromosome 22. Br J Haematol 87: 409-412, 1994.

6. Aurich J, Dastugue N, Duchayne E, Schlaifer D, Rigal-Huguet F and Caballin MR: Location of the BCR-ABL fusion gene on the 9q34 band in two cases of Ph-positive chronic myeloid leukemia. Genes Chromosomes Cancer 20: 148-154, 1997.

7. Brunel V, Sainty D, Costello R, Mozziconacci MJ, Simonetti J, Arnoulet C, Coignet L, Bouabdallah R, Gastaut JA, Gabert J and Lafage-Pochitaloff M: Translocation of BCR to chromosome 9 in a Philadelphia-negative chronic myeloid leukemia. Cancer Genet Cytogenet 85: 82-84, 1995.

8. Hsu WT, Preisler H, Szego K, Sprudzs R and Gao XZ: The $\mathrm{ABL} / \mathrm{BCR}$ fusion gene on chromosome 9 in $\mathrm{Ph}$-negative chronic myelogenous leukemia: a case for vigilance in fluorescence in situ hybridization interpretation. Cancer Genet Cytogenet 104: 57-60, 1998.

9. Michalova K, Zemanova Z, Bkezinova J, Moravcova J, Oltova A, Sobotka J, Kuglik P, Kozak T, Sindelarova L, Jankovska M, Obomilova A, Sieglova Z, Polak J, Nadvornikova S and Haskovec C: Location of the BCR/ABL fusion genes on both chromosomes 9q34 in Ph-negative chronic myeloid leukemia. Leuk Lymphoma 43: 1695-1700, 2002.

10. Takahashi N, Miura I, Ohshima A, Utsumi S, Nimura T, Hashimoto K, Saito M and Miura AB: Duplication of chromosome 9 carrying a BCR/ABL chimeric gene in Philadelphia chromosome-negative chronic myeloid leukemia. Cancer Genet Cytogenet 89: 166-169, 1996.

11. Al-Achkar W, Wafa A and Nweder MS: A complex translocation $\mathrm{t}(5 ; 9 ; 22)$ in Philadelphia cells involving the short arm of chromosome 5 in a case of chronic myelogenous leukemia. J Experimental Clin Cancer Res 26: 411-415, 2007. 
12. Shaffer L, Slovak M and Cambell L (eds): ISCN (2009): An International System for Human Cytogenetic Nomenclature. S. Karger, Basel, 2009.

13. Mitelman F, Johansson B and Mertens F (eds): Mitelman Database of Chromosome Aberrations in Cancer (2009). http:// cgap.nci.nih.gov/Chromosomes/Mitelman.

14. Morris CM, Heisterkamp N, Kennedy MA, Fitzgerald PH and Groffen J: Ph-negative chronic myeloid leukemia: molecular analysis of ABL insertion into M-BCR on chromosome 22. Blood 76: 1812-1818, 1990.
15. Virgili A, Brazma D, Reid AG, Howard-Reeves J, Valgañón M, Chanalaris A, De Melo VA, Marin D, Apperley JF, Grace C and Nacheva EP: FISH mapping of Philadelphia-negative BCR/ ABL1-positive CML. Mol Cytogenet 1: 14, 2008. 